\title{
Knowledge and Attitude of Nigerian Pregnant Women towards Antenatal Exercise: A Cross-Sectional Survey
}

\author{
Chidozie E. Mbada, ${ }^{1}$ Olubukayomi E. Adebayo, ${ }^{1}$ Adebanjo B. Adeyemi, ${ }^{2}$ Olujide O. Arije, ${ }^{3}$ \\ Olumide O. Dada, ${ }^{4}$ Olabisi A. Akinwande, ${ }^{5}$ Taofeek O. Awotidebe, ${ }^{1}$ and Ibidun A. Alonge ${ }^{4}$ \\ ${ }^{1}$ Department of Medical Rehabilitation, College of Health Sciences, Obafemi Awolowo University, Ile-Ife, Nigeria \\ ${ }^{2}$ Departments of Obstetrics, Gynaecology \& Perinatology, College of Health Sciences, Obafemi Awolowo University, Ile-Ife, Nigeria \\ ${ }^{3}$ Departments of Community Health, Obafemi Awolowo University Teaching Hospitals Complex, Ile-Ife, Nigeria \\ ${ }^{4}$ Department of Physiotherapy, University Health Services, University of Ibadan, Ibadan, Nigeria \\ ${ }^{5}$ Department of Physiotherapy, University College Hospital, Ibadan, Nigeria
}

Correspondence should be addressed to Chidozie E. Mbada; doziembada@yahoo.com

Received 19 February 2014; Accepted 19 March 2014; Published 14 April 2014

Academic Editors: D. Ayres-de-Campos and C. Iavazzo

Copyright (C) 2014 Chidozie E. Mbada et al. This is an open access article distributed under the Creative Commons Attribution License, which permits unrestricted use, distribution, and reproduction in any medium, provided the original work is properly cited.

Background. Engagement in physical exercise in pregnancy is hamstrung by safety concerns, skepticism about usefulness, and limited individualized prescription guidelines. This study assessed knowledge and attitude of pregnant women towards antenatal exercises (ANEx). Methods. The cross-sectional study recruited 189 pregnant women from six selected antenatal clinics in Ile-Ife, South-West, Nigeria. Data were obtained on maternal characteristics, knowledge, and attitude towards ANEx. Results. Relaxation and breathing (59.8\%), back care (51.3\%), and muscle strengthening (51.3\%) exercises were the most commonly known ANEx. Prevention of back pain risk (75.9\%) and excess weight gain (69.1\%) were perceived as benefits, while lower extremities swelling (31.8\%) and extreme weight gain or loss $(30.7 \%)$ were considered as contraindications to ANEx. $15.8 \%$ of the respondents had negative attitude towards ANEx resulting from insufficient information on exercise (83.3\%) and tiredness (70.0\%). Age significantly influences knowledge about contraindications to $\operatorname{ANEx}(P=0.001)$, while attitude was influenced by age and occupation, respectively $(P<0.05)$. There was significant association between attitude and knowledge about benefits and contraindications to ANEx $(P<0.05)$. Conclusion. A majority of Nigerian pregnant women demonstrated inadequate knowledge but had positive attitude towards ANEx. Knowledge about benefits and contraindications to ANEx significantly influenced the attitude towards exercise in pregnancy.

\section{Background}

Safe maternity with improved neonatal outcomes is predicated on proper antenatal care services $[1,2]$. Exercise has become a fundamental aspect of women's lives and an important constituent of antenatal care [3-5]. Wang and Apgar [6] submitted that empirical data on the impact of exercise on the mother, the fetus, and the course of pregnancy are still limited and results of the few studies in humans are often equivocal or contradictory. However, the American Congress of Obstetricians and Gynaecologists [3] recommended that pregnant women can exercise moderately for 30 minutes on most days of the week. In accordance with these recommendations, irrespective of the pregnant woman's physical fitness level, exercise should be low-impact, moderate-intensity, and regular [3, 7].

Studies have recommended that women should initiate or continue exercise in most pregnancies $[3,4,7]$ as it is safe for mother and not harmful to the foetus $[3,8,9]$. The health benefits of regular physical exercise in pregnancy include maintenance and improvement of physical fitness and cardiovascular endurance [4], prevention of excessive gestational weight gain and glucose intolerance [10, 11], conditioning of the muscles needed to facilitate labour $[7,12$, 13], and improvement in psychological adjustment to changes in pregnancy [4]. Furthermore, exercise in pregnancy is 
correlated with a decrease in many common problems of pregnancy [14] and the stress of exercises produces certain adaptation such as healthier placenta and increased ability to deal with short decrease in oxygen [15].

In spite of the fact that exercise programs during pregnancy and after childbirth are designed to minimize impairment and help the woman maintain or regain function while she is preparing for the arrival of the baby and then caring for the infant $[3,16,17]$, it is submitted that women are not meeting the exercise recommendations of the previous studies $[3,18,19]$. A myriad of factors not limited to beliefs and attitudes of women with respect to exercise in pregnancy [7, 20-22], level of knowledge [19, 22, 23], level of education [7], safety concern of the pregnant woman and her physician [6], race/ethnicity, and previous involvement in regular exercise have been implicated as important factors predisposing to exercise engagement or phobia among pregnant women. Thornton et al. [24] submitted that identifying factors that affect beliefs and behaviors would objectively encourage a change in attitude. Therefore, an assessment of knowledge and attitude about exercise in pregnancy may help to determine whether or not women will participate in exercise during and after pregnancy. This study was designed to assess knowledge and attitude of Nigerian pregnant women towards antenatal exercises.

\section{Methods}

One hundred and eighty-nine pregnant women were consecutively recruited into this cross-sectional survey. The respondents were recruited from six selected hospitals, namely, Urban Comprehensive Health Centre, Enuwa Primary Health centre, Comprehensive Health centre Aderemi, Obafemi Awolowo University (OAU) Health Centre, OAU Teaching Hospitals Complex, and Seventh Day Adventist Hospital in Ile-Ife, Osun state, South-West, Nigeria. Ethical approval for the study was obtained from the Health Research Ethics Committee of the Institute of Public Health, OAU, Ile-Ife, Nigeria (IPHOAU/12/13). Informed consent of all respondents was required for participation in the study.

The instrument for the study was an adapted questionnaire from a previous study by Ribeiro and Milanez [7] and was validated by expert reviews in a pilot study. The selfadministered questionnaire sought information on sociodemographic, knowledge and attitude towards exercise in pregnancy. The Yoruba version (the local language spoken in the area where the study was conducted) of the questionnaire was administered to respondents who were not literate in English. The reliability of the Yoruba version of the questionnaire was assessed by a test-retest method (by observing 7 days between test and retest) among 10 pregnant women attending the UCHC of the OAUTHC, Eleyele, Ile-Ife. The summation of all the checked items on the questionnaire at test and retest was compared. The questionnaire items yielded an agreement percentage that ranged from 87.4 to $99.6 \%$, the intraclass coefficient was 0.985 , and the confidence interval ranged from 0.94 to 0.996 . Pregnant women who were not literate in either English or Yoruba were excluded from the study.
TABLE 1: Sociodemographic characteristics of the respondents $(N=$ 189).

\begin{tabular}{lc}
\hline Variable & $n(\%)$ \\
\hline Religion & $145(76.7)$ \\
Christianity & $43(22.8)$ \\
Islam & $1(0.5)$ \\
Traditional religion & \\
Occupation & $23(12.2)$ \\
$\quad$ Home maker & $103(54.5)$ \\
Trading/business & $39(20.6)$ \\
Civil/public service & $20(10.6)$ \\
Schooling & $4(2.1)$ \\
Not specified & \\
Educational qualification & $9(4.8)$ \\
Primary & $49(25.9)$ \\
Secondary & $131(69.4)$ \\
Tertiary & \\
Income & $32(16.9)$ \\
Less than $\$ 100$ & $51(27.0)$ \\
\$100-\$200 & $38(20.1)$ \\
\$200-\$300 & $13(6.9)$ \\
\$300-\$500 & $10(5.3)$ \\
\$500-\$1000 & $10(5.3)$ \\
Greater than $\$ 1000$ & $25(13.2)$ \\
No Disclosure &
\end{tabular}

2.1. Data Analysis. Descriptive statistics of mean, standard deviation, and frequency distribution were used to summarize data. Inferential statistics of the Chi-square test was used to test the associations between knowledge and attitude of women towards antenatal exercises and the respondents' characteristics. Alpha level was set at 0.05 . Data was analyzed using Statistical Package for Social Sciences software version 16.0 (SPSS Inc., Chicago, USA).

\section{Results}

One hundred and eighty-nine respondents participated in this study. The mean age of the respondents was $28.9 \pm 4.63$ years. The sociodemographic characteristics of respondents are presented in Table 1 . The result shows that the respondents were preponderantly of Christian religion (76.7\%) and were traders or business women (54.5\%). A majority of the respondents had tertiary education (69.4\%) and were within the level of income of $\$ 100$ to $\$ 200$ per month (27.0\%). The maternal-obstetrics characteristics of respondents are presented in Table 2. A majority of the respondents were nulliparous (39.2\%) and commenced antenatal care within 1 to 3 months of pregnancy (28.6\%).

Respondents had knowledge of pelvic floor exercise (37.0\%), muscle strengthening exercise (51.3\%), back care exercise (51.3\%), and relaxation and breathing exercise (59.8\%), respectively, as types of antenatal exercise (Table 3). However, swimming (21.7\%) and cycling (20.6\%) were the least known types of exercises in pregnancy. Table 4 shows 
TABLE 2: Maternal-obstetric characteristics of the respondents $(N=$ 189).

\begin{tabular}{lc}
\hline Variable & $n(\%)$ \\
\hline Family setting & \\
Polygamy & $38(20.1)$ \\
Monogamy & $125(66.1)$ \\
Single parenting & $26(13.8)$ \\
Parity & \\
Nulliparous & $74(39.2 \%)$ \\
Primiparous & $53(28.0 \%)$ \\
Multiparous & $62(32.8 \%)$ \\
Mode of delivery & \\
Vaginal & $109(57.6 \%)$ \\
Caesarean section & $6(3.2 \%)$ \\
Not applicable & $74(39.2 \%)$ \\
Place of delivery & \\
Hospital & $93(49.2 \%)$ \\
Home & $7(3.7 \%)$ \\
Mission & $15(7.9 \%)$ \\
Not applicable & $74(39.2 \%)$ \\
Previous antenatal care start time & \\
<1 month & $5(2.6 \%)$ \\
1-3 months & $54(28.6 \%)$ \\
3-6 months & $44(23.3 \%)$ \\
6-9 months & $12(6.3 \%)$ \\
Not applicable & $74(39.2 \%)$ \\
Present antenatal care duration & \\
1-3 month & $75(39.7 \%)$ \\
3-6 months & $57(30.2 \%)$ \\
6-9 months & $44(23.2 \%)$ \\
\hline & $13(6.9 \%)$ \\
\hline
\end{tabular}

the knowledge of respondents' on benefits of and contraindications to antenatal exercises. Most of the respondents agreed that exercise in pregnancy would lead to reduction in risk of back pain (75.9\%), prevention of excess weight gain (69.1\%), and increased ability to cope with labour and delivery (69.6). On the other hand, lower extremities swelling $(31.8 \%)$, extreme weight gain or loss $(30.7 \%)$, and back pain (28.5\%) during pregnancy were mostly considered as contraindications to exercise during pregnancy. The summative knowledge score revealed that $47.6 \%$ of the respondents had below average knowledge and 5.82\% had average knowledge, while $46.6 \%$ had good knowledge of antenatal exercises.

Fifteen point eight percent of the respondents had negative attitude towards exercise. Lack of feeling to exercise (63.3\%), tiredness $(70.0 \%)$, and insufficient information on exercise $(83.3 \%)$ were the most implicated factors for negative attitude towards antenatal exercises (Table 5). There was no significant association between knowledge about benefits of antenatal exercises and respondents characteristics $(P>$ 0.05) (Table 6). However, there was significant association between knowledge about contraindications to antenatal exercises and age $(P=0.001)$ (Table 7$)$. Table 8 shows that
TABLE 3: Knowledge of respondents on different types of exercises in pregnancy $(N=189)$.

\begin{tabular}{lcc}
\hline Variable & Yes & No \\
& $n(\%)$ & $n(\%)$ \\
\hline Aerobics & $59(31.2)$ & $130(68.8)$ \\
Pelvic floor exercise & $70(37.0)$ & $119(63.0)$ \\
Swimming & $41(21.7)$ & $148(78.3)$ \\
Stretching exercise & $76(40.2)$ & $113(59.8)$ \\
Muscle strengthening exercise & $97(51.3)$ & $92(48.7)$ \\
Abdominal exercise & $56(29.6)$ & $133(70.4)$ \\
Back care exercise & $97(51.3)$ & $92(48.7)$ \\
Cycling & $39(20.6)$ & $150(79.4)$ \\
Relaxation and breathing exercise & $113(59.8)$ & $76(40.2)$ \\
\hline
\end{tabular}

age $(P=0.035)$ and occupation $(P=0.034)$ significantly influence attitude towards exercise in pregnancy. Furthermore, Chi-square test of association revealed a significant association between attitude and each piece of knowledge about benefit of $(P=0.001)$ and contraindication to $(P=$ 0.001 ) antenatal exercise (Table 9).

\section{Discussion}

This study assessed knowledge and attitude of Nigerian pregnant women towards antenatal exercises. The women in this study were generally young and were mostly Christians and traders or business persons. A majority of the women had tertiary education and were within the level of income of $\$ 100$ to $\$ 200$ per month $(27.0 \%)$. It has been found from previous studies that subjects' characteristics such as age [25], level of education $[7,19]$, and experience in infant and maternal issues [26] significantly influence knowledge, attitude, and perceptions of mothers towards exercises. Furthermore, most of the women in this study were nulliparous and commenced antenatal care within 1 to 3 months of pregnancy. This study's result on antenatal care commencement time is at variance with earlier findings of late antenatal care commencement among Nigerian [27-30] and other pregnant women from sub-Saharan Africa countries [31, 32]. The study's finding on antenatal care commencement time reflects an improvement in care seeking in pregnancy among Nigerian women. Therefore, it is believed that the findings of this study may have been influenced by the maternal sociodemographic characteristics.

Most of the women in this study had knowledge of pelvic floor exercise, muscle strengthening exercise, back care exercise, and relaxation and breathing exercise as types of antenatal exercises. However, swimming and cycling were mostly not known as types of antenatal exercises. Conversely, the American Pregnancy Association [33] ranked exercises in pregnancy in order as kegel, swimming, walking, bicycling, aerobics, and dance. It is adducible that the low level of knowledge of swimming among women in this study may not be unconnected with prevalent hydrophobia and cultural myths that makes swimming among pregnant women a taboo. In addition, lack of swimming skills and limited availability of swimming pools may have contributed to low 
TABLE 4: Knowledge of respondents' on benefits of and contraindications to antenatal exercises $(N=189)$.

\begin{tabular}{|c|c|c|c|c|}
\hline Items & Agree (\%) & $\mathrm{I}(\%)$ & DG $(\%)$ & AS (\%) \\
\hline \multicolumn{5}{|l|}{ Benefits } \\
\hline (1) Reduces risk of back pain during pregnancy & 75.9 & 18.4 & 5.8 & 84 \\
\hline (2) Prevents excessive weight gain during pregnancy & 69.1 & 23.3 & 7.7 & 79 \\
\hline (3) Increases risk of urinary incontinence during pregnancy & 41.3 & 43.8 & 14.7 & 69 \\
\hline (4) Increases risk of diabetes during pregnancy & 35.1 & 47.7 & 17.2 & 65 \\
\hline (5) Strengthens pelvic floor muscles during pregnancy & 54.3 & 37.0 & 8.8 & 73 \\
\hline (6) Increases formation of varicose veins during pregnancy & 35.3 & 55.9 & 8.8 & 68 \\
\hline (7) Increases risk of swelling of extremities during pregnancy & 56.9 & 37.3 & 5.8 & 76 \\
\hline (8) Causes high blood pressure during pregnancy & 58.4 & 35.1 & 6.6 & 76 \\
\hline (9) Increases muscle tone, strength, and endurance during pregnancy & 59.5 & 34.0 & 6.6 & 78 \\
\hline (10) Increased energy and stamina during pregnancy & 64.1 & 30.1 & 5.7 & 79 \\
\hline $\begin{array}{l}\text { (11) Improvement of body awareness, posture, coordination, and } \\
\text { balance during pregnancy }\end{array}$ & 63.8 & 31.5 & 4.6 & 80 \\
\hline (12) Better ability to cope with labour and delivery & 69.6 & 27.4 & 3.0 & 82 \\
\hline (13) More rapid postnatal recovery & 67.4 & 30.1 & 2.5 & 80 \\
\hline \multicolumn{5}{|l|}{ Contraindications } \\
\hline (1) Vaginal bleeding during pregnancy & 14.3 & 34.2 & 51.5 & 73 \\
\hline (2) Uterine contractions during pregnancy & 17.8 & 38.1 & 44.1 & 70 \\
\hline (3) Chest pain during pregnancy & 15.3 & 40.3 & 44.3 & 70 \\
\hline (4) Migraine during pregnancy & 12.1 & 43.0 & 44.9 & 71 \\
\hline (5) Difficulty in breathing during pregnancy & 16.5 & 38.9 & 44.6 & 70 \\
\hline (6) Swelling of the extremities during pregnancy & 31.8 & 42.2 & 26 & 62 \\
\hline (7) Back pain during pregnancy & 28.5 & 45.8 & 25.7 & 61 \\
\hline (8) Extreme weight gain or loss during pregnancy & 30.7 & 48.2 & 21.1 & 57 \\
\hline (9) Abdominal pain during pregnancy & 20.8 & 40.8 & 38.4 & 65 \\
\hline (10) Muscle weakness during pregnancy & 33.9 & 38.9 & 27.1 & 62 \\
\hline (11) Dizziness during pregnancy & 17.3 & 42.5 & 40.3 & 68 \\
\hline (12) Diabetes during pregnancy & 15.6 & 44.7 & 39.7 & 54 \\
\hline (13) Premature labour during pregnancy & 10.9 & 41.9 & 47.1 & 73 \\
\hline
\end{tabular}

Key: I: indifferent; DG: disagree; AS: average Score.

TABLE 5: Attitude of respondents towards antenatal exercises.

\begin{tabular}{lc}
\hline Variable & $n(\%)$ \\
\hline Attitude towards antenatal exercises $(N=189)$ & $159(84.1)$ \\
$\quad$ Positive & $30(15.8)$ \\
$\quad$ Negative & \\
Factors influencing negative attitude antenatal & \\
exercises $(n=30)$ & $21(70.0)$ \\
$\quad$ I feel tired to exercise & $19(63.3)$ \\
I do not feel like exercising & $9(30.0)$ \\
I have busy schedule & $6(20.0)$ \\
I have a lot of child care activities & $5(16.6)$ \\
I am afraid of exercise & $25(83.3)$ \\
I do not have sufficient information on exercise &
\end{tabular}

level of knowledge of swimming as an important antenatal exercise. Furthermore, cycling or riding a stationary bike is a far-flung antenatal exercise in the study setting and could be linked to nonavailability or nonaffordability of bicycle ergometer for personal use. More so, it is not advisable for pregnant women to ride conventional bicycles on most Nigerian roads as there are no dedicated bikeways.

With regard to knowledge about effect of exercise on pregnancy, most of the women in this study believe that antenatal exercise reduces risk of back pain, promotes better ability to cope with labour and delivery, and prevents excessive weight gain. These findings are consistent with previous reports $[12,34,35]$. In contrast to the American College of Obstetrician and Gynecologists [3] recommendation on contraindication to antenatal exercise, the women in this study mostly implicated swelling of the lower extremities, extreme weight gain or loss, and presence of back pain during pregnancy as contraindications to exercise during pregnancy. These conditions are at best relative contraindications which should not rule out engagement in exercise during pregnancy except there are underlying medical or obstetric complications. However, there is paucity of data on contraindications 
TABLE 6: Chi-square test of association between knowledge about benefits of antenatal exercises and respondents characteristics.

\begin{tabular}{|c|c|c|c|c|c|}
\hline & $\mathrm{BAK}(n=90)$ & $\mathrm{AK}(n=11)$ & $\operatorname{AAK}(n=88)$ & $X^{2}$ & $P$-value \\
\hline \multicolumn{6}{|l|}{ Age group } \\
\hline$<30$ years & $60(66.7 \%)$ & $3(27.3 \%)$ & $55(58.3 \%)$ & \multirow[t]{2}{*}{7.47} & \multirow{2}{*}{0.058} \\
\hline$\geq 30$ years & $30(33.3 \%)$ & $8(72.7 \%)$ & $33(41.7 \%)$ & & \\
\hline \multicolumn{6}{|l|}{ Educational qualification } \\
\hline Primary & $10(11.1 \%)$ & $3(27.3 \%)$ & $5(5.7 \%)$ & 8.53 & \multirow{3}{*}{0.202} \\
\hline Secondary & $26(28.9 \%)$ & $2(18.2 \%)$ & $23(26.1 \%)$ & & \\
\hline Tertiary & $54(60 \%)$ & $6(54.5 \%)$ & $60(68.2 \%)$ & & \\
\hline \multicolumn{6}{|l|}{ Occupation } \\
\hline Home maker & $11(12.6 \%)$ & $2(18.2 \%)$ & $11(12.5 \%)$ & 6.98 & \multirow{5}{*}{0.859} \\
\hline Trading/business & $45(50.0 \%)$ & $4(36.4 \%)$ & $44(50.0 \%)$ & & \\
\hline Civil/public service & $17(18.9 \%)$ & $4(36.4 \%)$ & $22(25.0 \%)$ & & \\
\hline Schooling & $13(14.4 \%)$ & $1(9.1 \%)$ & $7(8.0 \%)$ & & \\
\hline Not specified & $4(4.4 \%)$ & $0(0 \%)$ & $4(4.5 \%)$ & & \\
\hline \multicolumn{6}{|l|}{ Parity } \\
\hline Nulliparous & $19(21.1 \%)$ & $1(9.1 \%)$ & $19(21.6 \%)$ & 8.15 & \multirow{3}{*}{0.227} \\
\hline Primiparous & $35(38.9 \%)$ & $1(9.1 \%)$ & $31(35.2 \%)$ & & \\
\hline Multiparous & $36(40.0 \%)$ & $9(81.8 \%)$ & $38(43.2 \%)$ & & \\
\hline
\end{tabular}

Key: BAK: below average knowledge; AK: average knowledge; AAK: above average knowledge. Significance at $\boldsymbol{\alpha}=0.05$.

TABLE 7: Chi-square test of association between knowledge about contraindications to antenatal exercises and respondents characteristics.

\begin{tabular}{|c|c|c|c|c|c|}
\hline & $\mathrm{BAK}(n=90)$ & $\mathrm{AK}(n=11)$ & $\operatorname{AAK}(n=88)$ & $X^{2}$ & $P$-value \\
\hline \multicolumn{6}{|l|}{ Age group } \\
\hline$<30$ years & $65(62.5 \%)$ & $5(45.5 \%)$ & $52(61 \%)$ & 17.03 & \multirow{2}{*}{0.001} \\
\hline$\geq 30$ years & $39(37.5 \%)$ & $6(54.5 \%)$ & $36(39 \%)$ & & \\
\hline \multicolumn{6}{|l|}{ Educational qualification } \\
\hline Primary & $2(2.2 \%)$ & $2(18.2 \%)$ & $6(6.8 \%)$ & 9.58 & \multirow{3}{*}{0.143} \\
\hline Secondary & $27(30.0 \%)$ & $3(27.3 \%)$ & $20(22.7 \%)$ & & \\
\hline Tertiary & $61(67.8 \%)$ & $6(54.5 \%)$ & $62(70.5 \%)$ & & \\
\hline \multicolumn{6}{|l|}{ Occupation } \\
\hline Home maker & $15(16.7 \%)$ & $1(9.1 \%)$ & $14(15.9 \%)$ & 7.43 & \multirow{5}{*}{0.828} \\
\hline Trading/business & $36(40.0 \%)$ & $8(72.7 \%)$ & $40(45.5 \%)$ & & \\
\hline Civil/public service & $25(27.8 \%)$ & $1(9.1 \%)$ & $20(22.7 \%)$ & & \\
\hline Schooling & $11(12.2 \%)$ & $1(9.1 \%)$ & $9(10.2 \%)$ & & \\
\hline Not specified & $3(3.3 \%)$ & $0(0 \%)$ & $5(5.7 \%)$ & & \\
\hline \multicolumn{6}{|l|}{ Parity } \\
\hline Nulliparous & $21(21.5 \%)$ & $3(27.3 \%)$ & $14(15.9 \%)$ & 10.45 & \multirow{3}{*}{0.107} \\
\hline Primiparous & $38(38.5 \%)$ & $1(9.1 \%)$ & $33(37.5 \%)$ & & \\
\hline Multiparous & $31(40 \%)$ & $7(63.6 \%)$ & $41(46.6 \%)$ & & \\
\hline
\end{tabular}

Key: BAK: below average knowledge; AK: average knowledge; AAK: above average knowledge.

to exercise during pregnancy. Although, there appears to be lack of evidence on why pregnant women without medical conditions should not be allowed to engage in exercise, but some level of caution is needed in the presence of some respiratory conditions $[36,37]$ or orthopedic conditions such as back and hip pain or joint problems [12, 38, 39]. Nonetheless, the result of this study revealed that the knowledge about benefits of antenatal exercises was not influenced by maternal sociodemographic characteristics. However, age was found to significantly influence knowledge about contraindications to antenatal exercises.

About $16 \%$ of the women in this study demonstrated negative attitude towards exercise in pregnancy. Therefore, a majority of the study samples seem to have positive attitude towards antenatal exercises in pregnancy. This finding is in tandem with recent studies that have reported a positive 
TABLE 8: Chi-square test of association between attitude of respondents towards exercise and respondents' characteristics.

\begin{tabular}{|c|c|c|c|c|}
\hline & $\mathrm{NA}(n=30)$ & $\mathrm{PA}(n=159)$ & $X^{2}$ & $P$-value \\
\hline \multicolumn{5}{|l|}{ Age group } \\
\hline$<30$ years & $24(74.5 \%)$ & $95(59.4 \%)$ & 4.439 & \multirow{2}{*}{$0.035^{*}$} \\
\hline$\geq 30$ years & $6(25.5 \%)$ & $64(40.6 \%)$ & & \\
\hline \multicolumn{5}{|l|}{ Educational qualification } \\
\hline Primary & $3(10.0 \%)$ & $7(4.4 \%)$ & 5.708 & \multirow{3}{*}{0.058} \\
\hline Secondary & $12(40.0 \%)$ & $38(23.9 \%)$ & & \\
\hline Tertiary & $15(50.0 \%)$ & $114(71.7 \%)$ & & \\
\hline \multicolumn{5}{|l|}{ Occupation } \\
\hline Home maker & $8(26.7 \%)$ & $17(10.7 \%)$ & 10.400 & \multirow{5}{*}{$0.034^{*}$} \\
\hline Trading/business & $12(40.0 \%)$ & $82(51.6 \%)$ & & \\
\hline Civil/public service & $3(10.0 \%)$ & $38(23.9 \%)$ & & \\
\hline Schooling & $6(20.0 \%)$ & $15(9.4 \%)$ & & \\
\hline Not specified & $1(3.3 \%)$ & $7(4.4 \%)$ & & \\
\hline \multicolumn{5}{|l|}{ Parity } \\
\hline Nulliparous & $5(16.7 \%)$ & $33(20.8 \%)$ & 2.582 & \multirow{3}{*}{0.275} \\
\hline Primiparous & $15(50.0 \%)$ & $55(34.6 \%)$ & & \\
\hline Multiparous & $10(33.3 \%)$ & $71(44.7 \%)$ & & \\
\hline
\end{tabular}

Key: NA: negative attitude; PA: positive attitude; ${ }^{*}$ Significance at $\boldsymbol{\alpha}=0.05$.

TABLE 9: Chi-square test of association between attitude and knowledge about antenatal exercise.

\begin{tabular}{lccr}
\hline Value & NA $(n=30)$ & PA $(n=159)$ & $X^{2}$ \\
\hline Benefits of antenatal exercises & & & \\
Below average knowledge & $24(80.0 \%)$ & $67(42.1 \%)$ & 16.645 \\
Average knowledge & $2(6.7 \%)$ & $11(6.9 \%)$ & $0.001^{*}$ \\
Above average knowledge & $4(13.3 \%)$ & $86(54.1 \%)$ & \\
Contraindications to antenatal exercises & & $68(42.8 \%)$ & 13.305 \\
Below average knowledge & $23(76.7 \%)$ & $7(4.4 \%)$ & $0.001^{*}$ \\
Average knowledge & $2(6.7 \%)$ & $84(52.8 \%)$ & \\
Above average knowledge & $5(16.7 \%)$ & & \\
\hline
\end{tabular}

Key: NA: negative attitude; PA: positive attitude. ${ }^{*}$ Significance at $\boldsymbol{\alpha}=0.05$.

paradigm shift in attitudes toward exercise during pregnancy over the past two decades with increasing numbers of pregnant women participating in physical activities, exercises, and sports activities [3-5]. Improved knowledge of safety of exercise for both the mother and fetus during pregnancy in most cases has been linked to the willingness to initiate or continue antenatal exercises [3-5]. It was found in this study that attitude towards exercise in pregnancy was influenced mostly by tiredness, lack of feeling to exercise, and insufficient information on exercise. Similar findings have been reported by other authors $[7,19,20,40]$. Specifically, in the study by Duncombe et al. [21] the most reported reasons for not exercising during pregnancy included feeling too tired, uncomfortable or sick and being busy. Ribeiro and Milanez [7] submitted that the fact that the principal barriers to exercising described by the pregnant women were lack of time and feeling tired and uncomfortable may suggest that many women do not feel motivated to exercise despite being aware of the possible benefits that physical exercise could offer to their health and the health of their baby. However, the result of this study revealed that the age and occupation significantly influence attitude towards antenatal exercises in pregnancy. Furthermore, knowledge about benefit of and contraindication to antenatal exercise significantly influenced the attitude of the women towards exercise in pregnancy. This finding is consistent with previous reports that revealed significant association between adequate knowledge of antenatal exercises and attitudes toward exercise during pregnancy $[7,22,41]$.

This study provides an empirical data on knowledge and attitude of Nigerian pregnant women towards exercise in pregnancy. Hitherto, there is an apparent dearth of studies on exercise culture of women in sub-Sahara Africa. The outcomes of this study underscore the need of health education programmes on the importance of exercise in pregnancy among women from sub-Sahara Africa countries. Physical exercise plays a significant role in maternal health and creating awareness of its benefit and contraindications among local women of childbearing age will improve engagement in and attitude towards exercise, improve maternal outcomes, and eventually decrease the burden of pregnancy-related preventable conditions on the health care system. However, 
the outcome of this study is limited in its generalizability and needs to be validated in other settings.

\section{Conclusion}

A majority of Nigerian pregnant women demonstrated inadequate knowledge about antenatal exercises. However, the women had positive attitude towards exercise. Knowledge about benefit of and contraindication to antenatal exercise significantly influenced the attitude towards exercise in pregnancy.

\section{Conflict of Interests}

The authors declare that they have no conflict of interests regarding the publication of this paper.

\section{Acknowledgments}

The authors gratefully acknowledge all the women who volunteered for this study. Also, they are grateful to the administrative and nursing staff of the different hospitals selected for this survey.

\section{References}

[1] B. Palaniappan, "Role of antenatal care in safe motherhood," Journal of the Indian Medical Association, vol. 93, no. 2, pp. 5354, 1995.

[2] V. O. Awusi, E. B. Anyanwu, and V. Okeleke, "Determinants of antenatal care services utilization," Benin Journal of Postgraduate Medicine, vol. 11, no. 1, pp. 21-26, 2009.

[3] American Congress of Obstetricians and Gynaecologists (ACOG) and Committee on Obstetric Practice, "Exercise during pregnancy and the postpartum period. ACOG Committee Opinion Number 267," Obstetrics \& Gynecology, vol. 99, no. 1, pp. 171-173, 2002.

[4] L. A. Wolfe and G. A. L. Davies, "Canadian guidelines for exercise in pregnancy," Clinical Obstetrics and Gynecology, vol. 46, no. 2, pp. 488-495, 2003.

[5] R. Barakat, M. Pelaez, R. Montejo, M. Luaces, and M. Zakynthinaki, "Exercise during pregnancy improves maternal health perception: a randomized controlled trial," American Journal of Obstetrics and Gynecology, vol. 204, no. 5, pp. 402.e1-402.e7, 2011.

[6] T. W. Wang and B. S. Apgar, "Exercise during pregnancy," American Family Physician, vol. 57, no. 8, pp. 1846-1852, 1998.

[7] C. P. Ribeiro and H. Milanez, "Knowledge, attitude and practice of women in Campinas, São Paulo, Brazil with respect to physical exercise in pregnancy: a descriptive study," Reproductive Health, vol. 8, no. 1, p. 31, 2011.

[8] J. F. Clapp III, H. Kim, B. Burciu, and B. Lopez, "Beginning regular exercise in early pregnancy: effect on fetoplacental growth," American Journal of Obstetrics and Gynecology, vol. 183, no. 6, pp. 1484-1488, 2000.

[9] M. K. Riemann and I. K. Hansen, "Effects on the foetus of exercise in pregnancy," Scandinavian Journal of Medicine and Science in Sports, vol. 10, no. 1, pp. 12-19, 2000.

[10] L. Chasan-Taber, "Physical activity and dietary behaviors associated with weight gain and impaired glucose tolerance among pregnant Latinas," Advances in Nutrition, vol. 3, pp. 108-118, 2012.

[11] M. F. Mottola and S. M. Ruchat, "Exercise guidelines for women with gestational diabetes," in Gestational Diabetes by Miroslav Radenkovic, InTech, Rijeka, Croatia, 2011, http://www. intechopen.com/books/gestational-diabetes/exercise-guidelines-for-women-with-gestationaldiabetes.

[12] J. F. Clapp III, "The course of labor after endurance exercise during pregnancy," American Journal of Obstetrics and Gynecology, vol. 163 , no. 6, pp. 1799-1805, 1990.

[13] K. R. Kardel and T. Kase, "Training in pregnant women: effects on fetal development and birth," American Journal of Obstetrics and Gynecology, vol. 178, no. 2, pp. 280-286, 1998.

[14] P. Wadsworth, "The benefits of exercise in pregnancy," Journal for Nurse Practitioners, vol. 3, no. 5, pp. 333-339, 2007.

[15] D. M. Donald, "Lower back pain during pregnancy," Nursing Journal of India, vol. 12, no. 15, pp. 43-49, 1994.

[16] S. Mørkved, K. Bø, B. Schei, and K. Å. Salvesen, "Pelvic floor muscle training during pregnancy to prevent urinary incontinence: a single-blind randomized controlled trial," Obstetrics and Gynecology, vol. 101, no. 2, pp. 313-319, 2003.

[17] R. Stephenson and L. O'Connor, Obstetric and Gynaecologic Care in Physical Therapy, Charles B. Slack, Thorofare, NJ, USA, 2ndn edition, 2000.

[18] J. M. Pivarnik, H. O. Chambliss, J. F. Clapp et al., "Impact of physical activity during pregnancy and postpartum on chronic disease risk," Medicine and Science in Sports and Exercise, vol. 38, no. 5, pp. 989-1006, 2006.

[19] K. R. Evenson, M. Moos, K. Carrier, and A. M. Siega-Riz, "Perceived barriers to physical activity among pregnant women," Maternal and Child Health Journal, vol. 13, no. 3, pp. 364-375, 2009.

[20] P. Clarke and H. Gross, "Women's behaviour, beliefs and information sources about physical exercise in pregnancy," Midwifery, vol. 20, no. 2, pp. 133-141, 2004.

[21] D. Duncombe, E. H. Wertheim, H. Skouteris, S. J. Paxton, and L. Kelly, "Factors related to exercise over the course of pregnancy including women's beliefs about the safety of exercise during pregnancy," Midwifery, vol. 25, no. 4, pp. 430-438, 2009.

[22] E. E. Krans, J. G. Gearhart, P. M. Dubbert, P. M. Klar, A. L. Miller, and W. H. Replogle, "Pregnant women's beliefs and influences regarding exercise during pregnancy," Journal of the Mississippi State Medical Association, vol. 46, no. 3, pp. 67-73, 2005.

[23] C. F. Moran, V. L. Holt, and D. P. Martin, "What do women want to know after childbirth?” Birth, vol. 24, no. 1, pp. 27-34, 1997.

[24] P. L. Thornton, E. C. Kieffer, Y. Salabarría-Peña et al., "Weight, diet, and physical activity-related beliefs and practices among pregnant and postpartum latino women: the role of social support," Maternal and Child Health Journal, vol. 10, no. 1, pp. 95-104, 2006.

[25] J. Zhang and D. A. Savitz, "Exercise during pregnancy among US women," Annals of Epidemiology, vol. 6, no. 1, pp. 53-59, 1996.

[26] H. M. Whitford, B. Alder, and M. Jones, "A cross-sectional study of knowledge and practice of pelvic floor exercises during pregnancy and associated symptoms of stress urinary incontinence in North-East Scotland," Midwifery, vol. 23, no. 2, pp. 204-217, 2007.

[27] P. N. Ebeigbe and G. O. Igberase, "Antenatal care: a comparison of demographic and obstetric characteristics of early and late attenders in the Niger Delta, Nigeria," Medical Science Monitor, vol. 11, no. 11, pp. 529-532, 2005. 
[28] E. P. Ndidi and I. G. Oseremen, "Reasons given by pregnant women for late initiation of antenatal care in the Niger Delta, Nigeria," Ghana Medical Journal, vol. 44, no. 2, pp. 47-51, 2010.

[29] M. A. Okunlola, K. M. Owonikoko, A. O. Fawole, and A. O. Adekunle, "Gestational age at antenatal booking and delivery outcome," African Journal of Medicine and Medical Sciences, vol. 37, no. 2, pp. 165-169, 2008.

[30] D. A. Adekanle and A. I. Isawumi, "Late antenatal care booking and its predictors among pregnant women in South Western Nigeria," Online Journal of Health and Allied Sciences, vol. 7, no. 1, pp. 4-7, 2008.

[31] M. S. Kiwuwa and P. Mufubenga, "Use of antenatal care, maternity services, intermittent presumptive treatment and insecticide treated bed nets by pregnant women in Luwero district, Uganda," Malaria Journal, vol. 7, p. 44, 2008.

[32] M. Mrisho, B. Obrist, J. A. Schellenberg et al., "The use of antenatal and postnatal care: perspectives and experiences of women and health care providers in rural southern Tanzania," BMC Pregnancy and Childbirth, vol. 9, p. 10, 2009.

[33] "American Pregnancy Association (APA): 'Top recommended exercises," 2008, http://www.americanpregancy.org/ .

[34] V. E. Pennick and G. Young, "Interventions for preventing and treating pelvic and back pain in pregnancy," Cochrane Database of Systematic Reviews, no. 21, Article ID CD001139, p. 8, 2007.

[35] D. Symons Downs and H. A. Hausenblas, "Women's exercise beliefs and behaviors during their pregnancy and postpartum," Journal of Midwifery and Women's Health, vol. 49, no. 2, pp. 138144, 2004.

[36] R. Artal, L. D. Platt, and M. Sperling, "Exercise in pregnancy. I. Maternal cardiovascular and metabolic responses in normal pregnancy," American Journal of Obstetrics and Gynecology, vol. 140, no. 2, pp. 123-127, 1981.

[37] C. A. Collings, L. B. Curet, and J. P. Mullin, "Maternal and fetal responses to a maternal aerobic exercise program," American Journal of Obstetrics and Gynecology, vol. 145, no. 6, pp. 702707, 1983.

[38] E. A. Lokey, Z. V. Tran, C. L. Wells, B. C. Myers, and A. C. Tran, "Effects of physical exercise on pregnancy outcomes: a metaanalytic review," Medicine and Science in Sports and Exercise, vol. 23, no. 11, pp. 1234-1239, 1991.

[39] J. C. Veille, A. R. Hohimer, K. Burry, and L. Speroff, "The effect of exercise on uterine activity in the last eight weeks of pregnancy," American Journal of Obstetrics and Gynecology, vol. 151, no. 6, pp. 727-730, 1985.

[40] J. Cioffi, V. Schmied, H. Dahlen et al., "Physical activity in pregnancy: women's perceptions, practices, and influencing factors," Journal of Midwifery and Women's Health, vol. 55, no. 5, pp. 455-461, 2010.

[41] M. Abedzadeh, M. Taebi, Z. Sadat, and F. Saberi, "Knowledge and performance of pregnant women referring to Shabihkhani hospital on exercises during pregnancy and postpartum periods," Journal of Jahrom University of Medical Sciences, vol. 8, no. 4, 2011. 


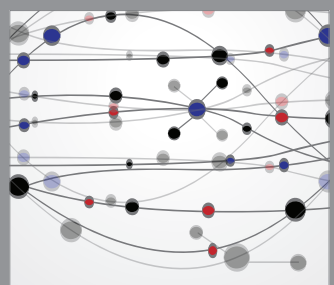

The Scientific World Journal
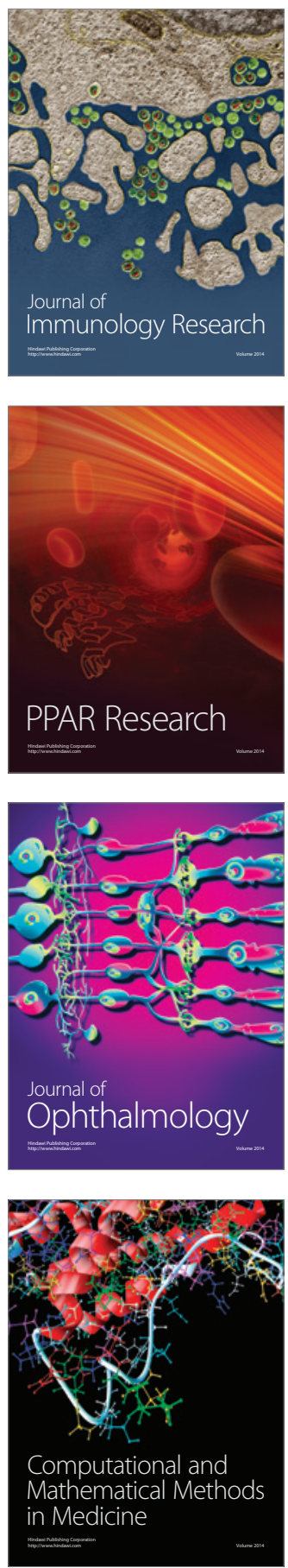

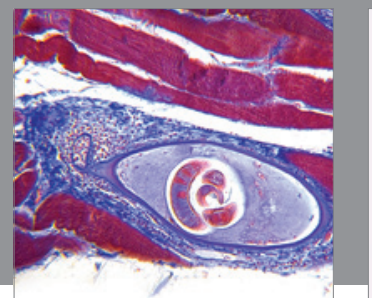

Gastroenterology

Research and Practice
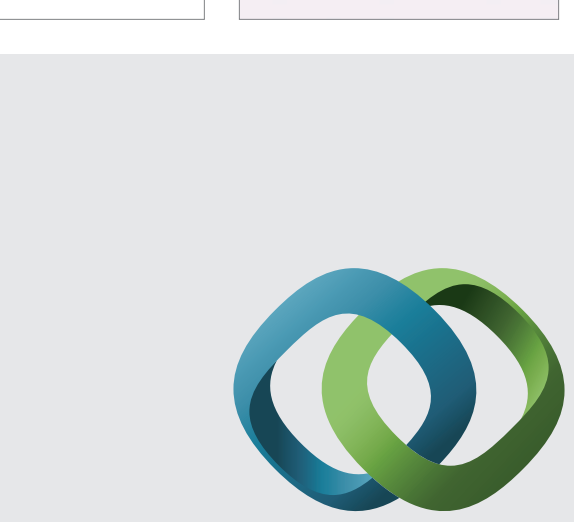

\section{Hindawi}

Submit your manuscripts at

http://www.hindawi.com
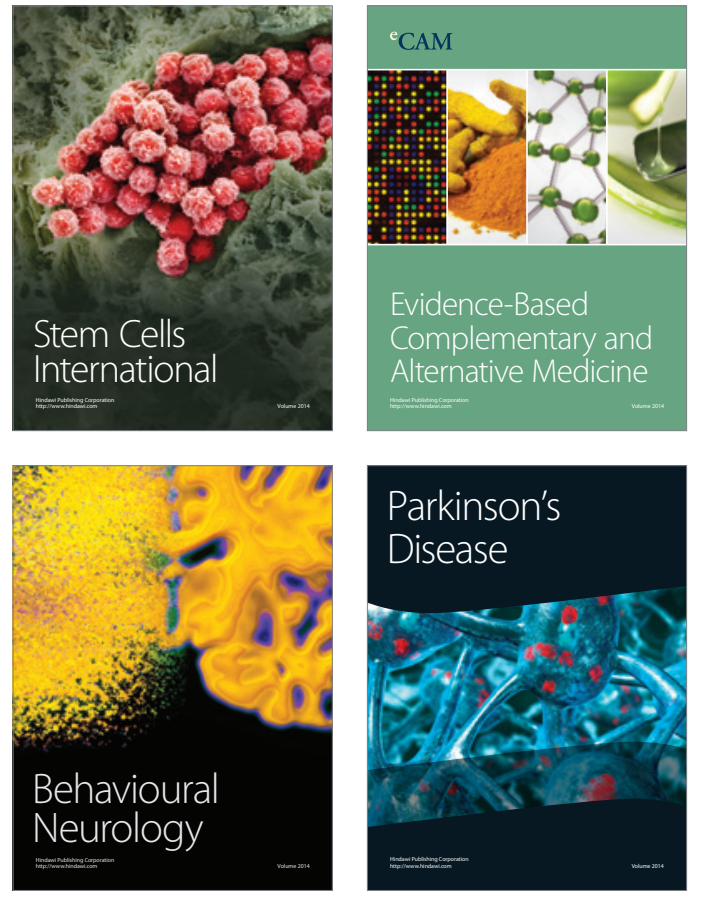
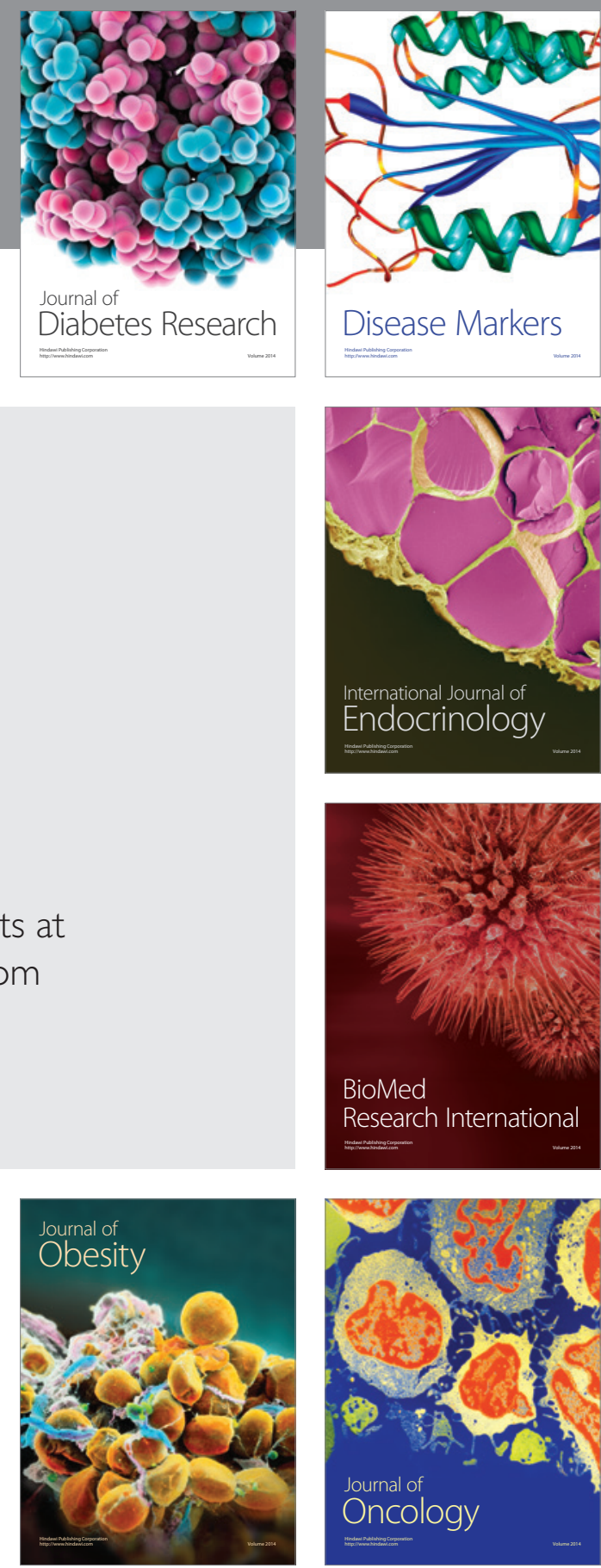

Disease Markers
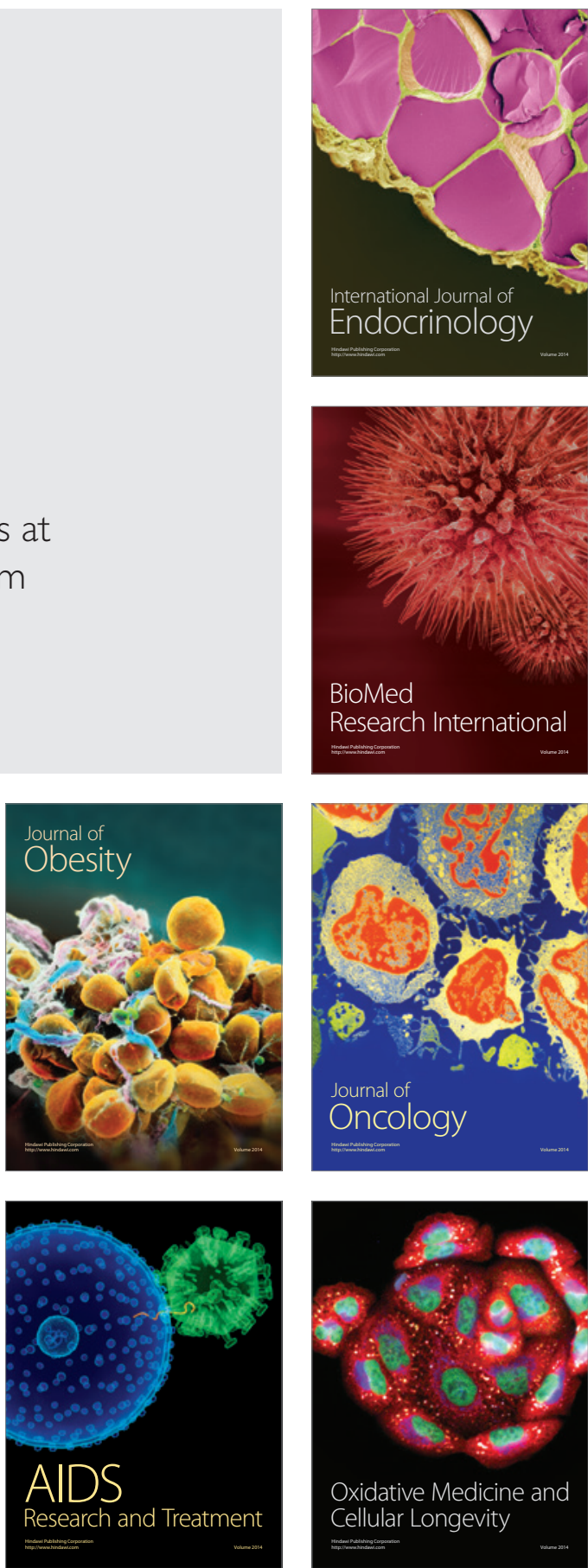